\title{
Evaluatie van twee intensieve behandelingsschema's tegen Psoroptes ovis-schurft bij Belgisch witblauwe runderen op negen Vlaamse rundveebedrijven
}

\section{Evaluation of two intensive treatment schedules against Psoroptes ovis mange in Belgian blue cattle on nine Flemish farms}

\author{
${ }^{1}$ C. Sarre, ${ }^{2}$ T. Geurden, ${ }^{1}$ J. Vercruysse, ${ }^{1}$ N. De Wilde, ${ }^{1}$ S. Casaert, ${ }^{1}$ E. Claerebout \\ ${ }^{1}$ Vakgroep Virologie, Parasitologie en Immunologie, Faculteit Diergeneeskunde, Universiteit Gent, \\ Salisburylaan 133, B-9820 Merelbeke, België \\ ${ }^{2}$ Zoetis Belgium s.a., Mercuriusstraat 20, B-1930 Zaventem, België
}

Charlotte.Sarre@UGent.be

\section{AMENVATTING}

Schurft veroorzaakt door Psoroptes ovis komt voor op de meeste Vlaamse bedrijven met Belgisch witblauw vleesvee. In deze studie werden twee intensieve behandelingsschema's geëvalueerd op negen Vlaamse vleesveebedrijven met een persisterend schurftprobleem. Op bedrijf 1 tot en met 7 werden alle dieren tweemaal behandeld (met een interval van zeven à tien dagen) met een injecteerbaar macrocyclisch lacton (ML). Op de twee laatste bedrijven werd een eenmalige injectie gegeven met de 'long acting'-formulatie (LA) van moxidectine (10\%). Na behandeling werden huidafkrabsels genomen en bij de aanwezigheid van levende mijten bij ten minste één dier werden alle dieren (bedrijven 1 tot en met 7) of enkel de positieve dieren (bedrijf 8 en 9) verder behandeld met een injecteerbaar ML. Op alle bedrijven waren de dieren klinisch genezen en schijnbaar vrij van mijten na twee tot negen behandelingsrondes (twee injecties met zeven à tien dagen interval of één LA-injectie). Hoewel er op de eerste zeven bedrijven na het daaropvolgende weideseizoen opnieuw tekenen van schurft te zien waren, was dit in mindere mate en de schurft was gemakkelijker onder controle te houden.

\section{ABSTRACT}

Psoroptic mange, caused by Psoroptes ovis, is a problem on many Flemish farms where Belgian blue beef cattle are bred. Two intensive treatment schedules were evaluated on nine Belgian blue farms with a persistent mange problem. On farms 1 to 7 , all animals were treated twice (with a seven-to-tendays interval) with an injectable macrocyclic lactone (ML), while on the two remaining farms, the initial treatment consisted of one injection with the long acting (LA) formulation of moxidectin (10\%). Skin scrapings were taken after treatment, and when living mites were found on at least one animal, all animals (farms 1 to 7 ) or only positive animals (farms 8 and 9) were treated consecutively with an injectable ML. On all farms, the treated animals were clinically healthy and $P$. ovis free at the end of winter, after two to nine treatment rounds (two injections with a seven to ten-days interval or one LA injection). Although mange reappeared on the first seven farms after the subsequent grazing season, the disease was less severe and easier to control.

\section{INLEIDING}

Schurft is een veel voorkomende parasitaire huidinfectie bij runderen in België en wordt veroorzaakt door schurftmijten. Er bestaan vier soorten mijten bij het rund: Demodex bovis, Sarcoptes scabiei, Chorioptes bovis en Psoroptes ovis. De haarfollikelmijt Demodex bovis leeft als commensaal op de huid van het rund, maar kan in bepaalde gevallen kleine cutane nodulen veroorzaken. Infecties met $S$. scabiei zijn bij Vlaamse runderen een zeldzaamheid geworden. $C$. bovis komt voornamelijk voor bij melkvee en veroorzaakt 'pootschurft', die meestal een vrij goedaardig verloop kent. De meest voorkomende soort schurft bij het Belgisch witblauwe (BWB) vleesvee wordt veroorzaakt door $P$. ovis-mijten en wordt ook 'natte schurft' genoemd. Het BWB-ras is bovendien overgevoelig voor deze infectie (Losson et al., 1999). Kli- 
nisch wordt een allergische dermatitis waargenomen met papels, vochtige korsten, alopecia en lichenificatie, vooral ter hoogte van schoft, rug en staartbasis (Figuur 1). Gegeneraliseerde letsels kunnen eveneens voorkomen en worden vaak secundair bacterieel besmet. Door de intense jeuk gaan de dieren schuren, met complicaties, zoals hematomen en abcessen, tot gevolg (Aiello, 1998; Taylor et al., 2007). Naast een verminderd dierenwelzijn heeft deze infestatie ook een verminderde productie tot gevolg, bestaande uit een verminderde groei en lederkwaliteit en behandelingskosten voor de veehouder (Cole en Guillot, 1987; Lonneux et al., 1998; Rehbein et al., 2003; Stromberg et al., 1989). Psoroptes spp.-schurft wordt het best behandeld met een injecteerbaar macrocyclisch lacton (ML) of door topicaal gebruik van amitraz (Intervet Int. via MSD AH, België), waarbij alle in-contactdieren tegelijk behandeld worden (Taylor et al., 2007). De dieren moeten minimum tweemaal behandeld worden met een interval van zeven à tien dagen (Lonneux et al., 1997; O'Brien, 1999; Personne et al., 2006; Vercruysse en Rew, 2002). Indien met een "long acting" (LA)-formulatie van moxidectine (10\%) (Cydectin $10 \%$ LA, Zoetis, België) wordt behandeld, kan één behandeling voldoende zijn (Losson et al., 2008). Het vooraf scheren en verwijderen van de meeste korsten heeft een gunstig effect op de genezing (Plant, 2006).

In een studie uitgevoerd op Vlaamse rundveebedrijven werd aangetoond dat de bedrijfsprevalentie van schurft op vleesveebedrijven in Vlaanderen ongeveer $75 \%$ bedraagt (Sarre et al., 2012). Hoewel veel bedrijven besmet zijn, worden tussen verschillende bedrijven grote verschillen opgemerkt wat de ernst van de aandoening betreft. Algemene managementfactoren, zoals hygiëne (frequentie van het instrooien) en aankoopbeleid, kunnen hierbij een rol spelen (Sarre et al., 2012). Naast deze risicofactoren werd ook aangetoond dat $75 \%$ van de ondervraagde veehouders een incorrect behandelingsschema aanhoudt, waarbij vooraf geen diagnose gesteld wordt, een verkeerde formulatie van het product wordt gebruikt, slechts

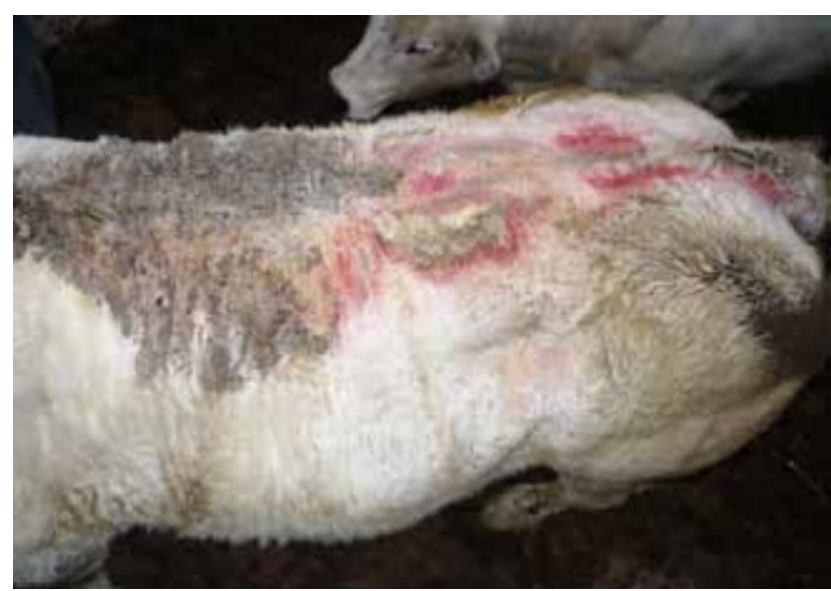

Figuur 1. Dorsaal zicht van een met $P$. ovis aangetaste BWB-koe.

eenmalig behandeld wordt of een te lang interval tussen twee behandelingen gelaten wordt of waarbij enkel de klinisch aangetaste dieren een behandeling ondergaan (Sarre et al., 2012). Ook dit kan aan de basis liggen van persisterende schurftproblemen op sommige bedrijven.

Het doel van deze studie was nagaan of een $P s o$ roptes-schurftinfectie onder controle kon gekregen worden op negen vleesveebedrijven met een chronisch schurftprobleem, aan de hand van een intensief behandelingsschema in combinatie met een geoptimaliseerd bedrijfsmanagement.

\section{MATERIAAL EN METHODEN}

Er werden negen bedrijven met BWB-dieren opgevolgd gedurende één volledige stalperiode (in de winter van 2012-2013, 2013-2014 of 2014-2015) (Tabel 1). De bedrijven werden aangebracht door de veehouders of door de bedrijfsdierenarts omdat reeds jaren schurft op het bedrijf aanwezig was en de veehouder aangaf dat het probleem moeilijk tot niet onder controle te krijgen was.

Tabel 1. Schematische voorstelling van het aantal behandelingsrondes en het gebruikte acaricide per bedrijf.

\begin{tabular}{clcll}
\hline Bedrijf & Provincie & n rund & n Tx** & Acaricide \\
\hline 1 & Vlaams-Brabant & 50 & 3 & Doramectine \\
2 & Limburg & 40 & 2 & Doramectine \\
3 & Oost-Vlaanderen & 300 & 4 & Ivermectine en amitraz \\
4 & Oost-Vlaanderen & 250 & 3 & Ivermectine en amitraz \\
5 & West-Vlaanderen & 200 & 3 & Ivermectine en doramectine \\
6 & West-Vlaanderen & 350 & 9 & Ivermectine \\
7 & Oost-Vlaanderen & 90 & 4 & Ivermectine en amitraz \\
8 & West-Vlaanderen & 15 & $4^{\circ}$ & Moxidectine LA \\
9 & Oost-Vlaanderen & 15 & $3^{\circ}$ & Moxidectine LA \\
\hline
\end{tabular}

* Aantal opgevolgde runderen.

** Aantal behandelingsrondes voordat het bedrijf vrij verklaard kon worden.

${ }^{\circ}$ De eerste behandelingsronde bestaat uit een eenmalige injectie met moxidectine $10 \%$ LA en bijkomende behandelingsrondes bestaan uit dubbele injecties met moxidectine $1 \%$ (interval 7 à 10 dagen). 
Tijdens een eerste bedrijfsbezoek werden huidstalen genomen van minimum 5\% van het totaal aantal runderen op het bedrijf, verspreid over alle stallen, om een inschatting te maken van de ernst van het probleem en het soort schurft per stal (P. ovis, C. bovis of menginfectie). Per rund werd ter hoogte van de klinische letsels telkens een oppervlakte van $3 \mathrm{~cm} \times 2 \mathrm{~cm}$ afgekrabd met een scalpelmesje. Met behulp van een stereomicroscoop (vergroting x25) werd dit afkrabsel direct onderzocht op levende (beweeglijke) mijten, waarna uit elk staal tien levende mijten geïsoleerd en opgeklaard werden in lactofenol ter differentiatie van de species. De negatieve stalen werden 12 uur geïncubeerd bij $37^{\circ} \mathrm{C}$ in $10 \% \mathrm{KOH} \mathrm{(v/v)} \mathrm{voor} \mathrm{indirect} \mathrm{on-}$ derzoek. Na centrifugatie ( 5 minuten, $3000 \mathrm{~g}$ ) werden de mijten uit het sediment opgezuiverd door flotatie met een sucroseoplossing (specifieke densiteit 1,27) waarna ze microscopisch geïdentificeerd werden (vergroting $\mathrm{x} 100$ ). Enkel bedrijven waar $P$. ovis aanwezig was (zuiver of menginfectie met $C$. bovis), werden verder opgevolgd.

Er werd op alle bedrijven aangeraden specifieke managementmaatregelen toe te passen, zoals het vooraf scheren van de dieren (minstens de rug) bij het opstarten van de behandeling, het regelmatig instrooien van de boxen en aangekochte dieren behandelen en in quarantaine houden gedurende twee à drie weken (Lusat et al., 2009).

Vervolgens werd een van twee behandelingsprotocollen opgestart, waarbij de dieren verscheidene behandelingsrondes ondergingen (Figuur 2). Op bedrijf 1 tot en met 7 werd het eerste protocol toegepast, waarbij alle dieren een eerste behandelingsronde ondergingen. Een behandelingsronde tegen $P$. ovisschurft bestaat standaard uit het tweemaal behandelen van alle dieren met een injecteerbaar ML naar keuze aan de voorgeschreven dosering, met een interval van zeven à tien dagen. Idealiter worden de dieren gewogen om de dosis van het gebruikte ML te bepalen, maar in deze studie werd het gewicht van de dieren geschat. Eén week na deze behandelingsronde werden opnieuw stalen genomen, ditmaal van alle nog zichtbaar aangetaste dieren. Op deze stalen werd enkel direct onderzoek uitgevoerd, aangezien na behandeling enkel actieve infecties met levende mijten opgespoord dienden te worden. Wanneer minimum één staal positief was, werd opnieuw bij alle dieren een behandelingsronde doorgevoerd. Wanneer bij de volgende monstername, één week na behandeling, opnieuw positieve dieren aanwezig waren, werd uit praktische en economische overwegingen enkel bij de positieve dieren een behandelingsronde uitgevoerd. Bij het tweede behandelingsprotocol (bedrijf 8 en 9) bestond de eerste behandelingsronde uit een eenmalige injectie met de LA-formulatie van moxidectine (Cydectin 10\% LA, Zoetis, België). Bijkomende behandelingen gebeurden enkel op de aangetaste dieren waarbij behandelingsrondes met de kortwerkende injecteerbare formulatie van moxidectine (Cydectin $1 \%$, Zoetis, België) werden toegepast (tweemaal met

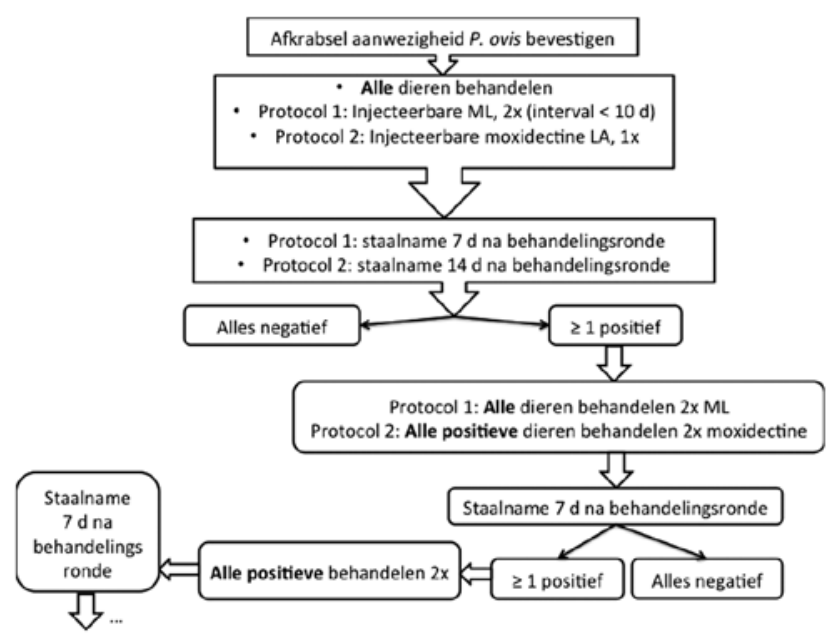

Figuur 2. Schematisch overzicht van de gebruikte behandelingsprotocollen.

zeven tot tien dagen interval). Dit behandelings- en bemonsteringsschema werd volgehouden tot alle dieren parasitologisch negatief en/of klinisch genezen waren.

Bij het eerste protocol werd het al dan niet slagen van de behandelingen geëvalueerd aan de hand van de aanwezigheid van zichtbare, actieve, klinische letsels (erythema, korsten en/of schilfers, natte huid) in combinatie met de aanwezigheid van levende $P$. ovismijten, uitgedrukt als het percentage positieve bemonsterde dieren. Deze evaluatiecriteria werden bij het tweede protocol aangevuld met bijkomende parameters. Er werd een "scratching index" (SI) bepaald, waarbij gedragingen gelinkt aan jeuk (likken, schuren, krabben) geteld werden gedurende tien minuten en gedeeld werden door het totaal aantal geobserveerde dieren. Bovendien werd per dier een "clinical index" (CI) berekend door de oppervlakte aangetaste huid aan te duiden op een rooster volgens de methode van Guillot (1981). Daarnaast werd voor elk dier het aantal mijten geteld in het afkrabsel, i. e. "mite count" (MC).

Vóór het inweiden werden op bedrijf 1 tot en met 7 opnieuw stalen genomen van minimum $50 \%$ van de opgevolgde dieren, waarbij asymptomatische dieren bemonsterd werden ter hoogte van de predilectieplaatsten van zowel $P$. ovis- als $C$. bovis-schurft. Op deze bedrijven werd één jaar later, bij het terug opstallen van de dieren, opnieuw een staalname uitgevoerd op 5\% van de totale kudde om de infestatie na de weidegang te evalueren.

\section{RESULTATEN}

Enkel op bedrijf twee werden de adviezen omtrent management niet volledig opgevolgd, waarbij de dieren niet geschoren werden vóór de behandeling.

De meest gebruikte producten waren ivermectine en doramectine (Eli Lilly, België) (bedrijf 1 tot en met 7) naast moxidectine (bedrijf 8 en 9) (Tabel 1). 

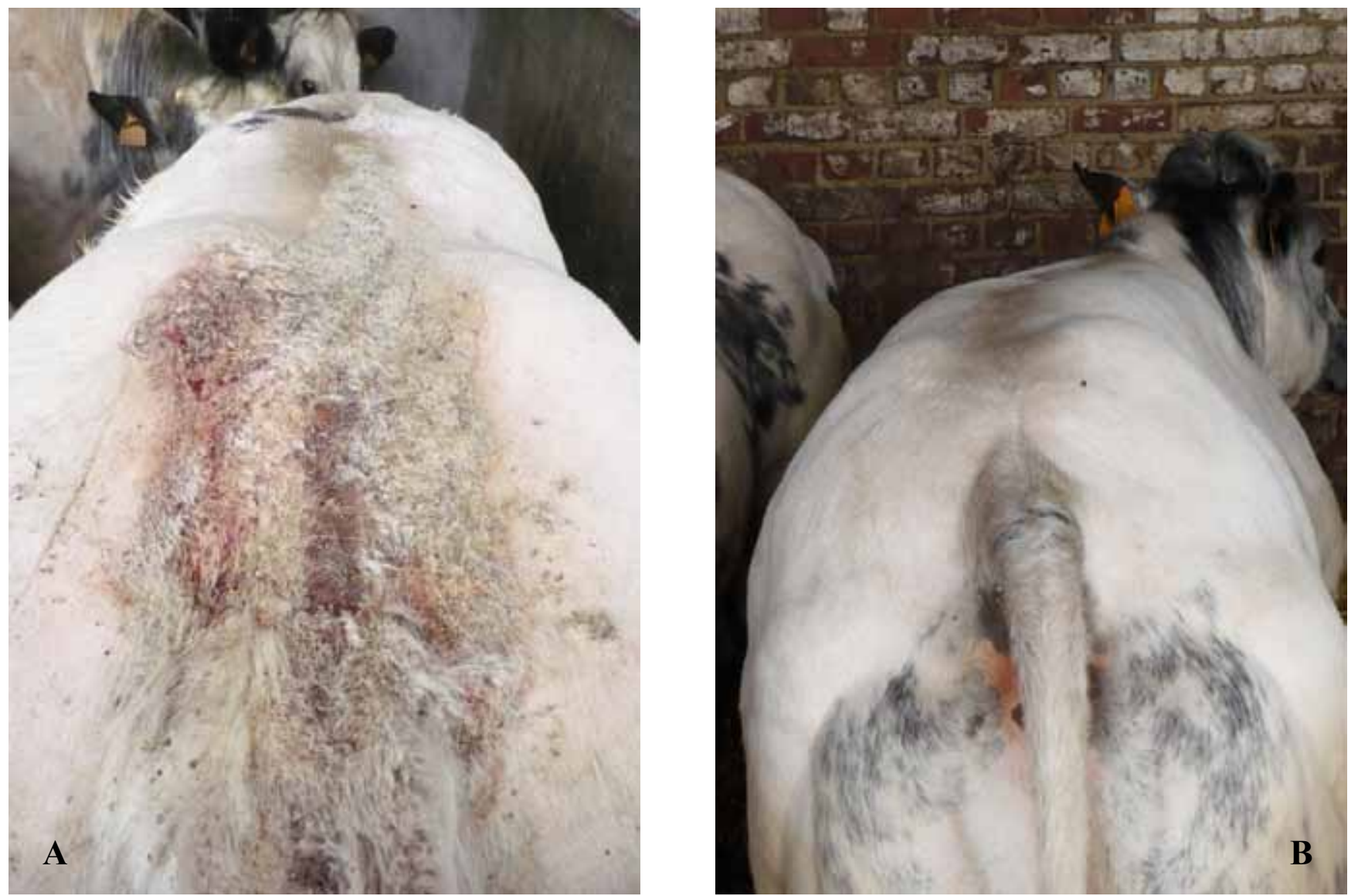

Figuur 3A en B. Voorbeeld van aangetast dier A. vóór en B. na behandeling.

Op drie bedrijven (bedrijf 3, 4 en 7) werden sommige runderen (bijkomend) tweemaal behandeld met amitraz (Intervet Int. via MSD AH, België), met een interval van zeven à tien dagen, wanneer een menginfectie met $C$. bovis aanwezig was of wanneer dieren vetgemest werden en producten met een korte wachttijd nodig waren.

Alle opgevolgde bedrijven konden na één winterperiode schurftvrij verklaard worden (Figuur 3). Bedrijf 1 tot en met 7 werd als schurftvrij beschouwd als alle dieren op het bedrijf klinisch genezen waren en/of als tijdens het laatste bedrijfsbezoek alle bemonsterde dieren parasitologisch negatief waren. Op bedrijf 8 en 9 waren de dieren schurftvrij wanneer daarnaast ook de MC negatief waren. Om tot een schurftvrije bedrijfssituatie te komen, waren gemiddeld vier behandelingsrondes nodig, met een minimum van twee en een maximum van negen behandelingsrondes (Tabel 1). Het percentage dieren met levende mijten na elke behandelingsronde per bedrijf wordt voorgesteld in Tabel 2. In Tabel 3 worden de SI, $\mathrm{CI}$ en MC van de positief bevonden dieren na behandeling op bedrijf 8 en 9 voorgesteld. Op bedrijf 3,5 en 7 werden de laatste runderen (respectievelijk nog 3, 1 en 1 dier(en)) behandeld net vóór de kudde ingeweid werd, waardoor geen controlestalen meer genomen konden worden. Er kon dus parasitologisch niet bevestigd worden dat het bedrijf schurftvrij was, maar de dieren waren wel klinisch genezen. Op bedrijf 6 werd de zevende en achtste injectie kort na de zesde behandeling uitgevoerd zonder tussentijdse monstername, aangezien de veehouder net na de behandeling van de laatste twee positieve dieren opnieuw symptomen opgemerkt had bij een andere groep dieren en deze aansluitend ook tweemaal behandeld had.

Eén jaar na het starten van de opvolging werd een controlebezoek uitgevoerd op bedrijf 1 tot en met 7 bij het opstallen van de dieren. Op deze bedrijven werden opnieuw symptomen van schurft en levende mijten vastgesteld na de weidegang, maar volgens de veehouders was de situatie minder ernstig dan de vorige jaren. Er waren minder dieren aangetast en het ging in de meeste gevallen over mildere symptomen dan de vorige jaren (kleinere letsels en minder letsels per dier). Alle veehouders pasten op eigen initiatief het standaard behandelingsprotocol opnieuw toe en gaven aan sneller van het schurftprobleem verlost te zijn (er waren meestal slechts twee behandelingsrondes nodig).

\section{DISCUSSIE}

In deze studie werden twee intensieve behandelingsschema's tegen schurft getest op vleesveebedrijven met chronische schurftproblemen. Hoewel de bedrijfsprevalentie van schurft op Vlaamse vleesveebedrijven zeer hoog is $(75 \%)$, vormen probleembe- 
Tabel 2. Percentage (\%) en aantal dieren met levende mijten op het totale aantal bemonsterde dieren na elke behandelingsronde per bedrijf ( $\mathrm{n}=$ aantal behandelingsrondes).

\begin{tabular}{|c|c|c|c|c|c|c|c|c|c|}
\hline n behandelingsrondes & Bedrijf 1 & Bedrijf 2 & Bedrijf 3 & Bedrijf 4 & Bedrijf 5 & Bedrijf 6 & Bedrijf 7 & Bedrijf 8 & Bedrijf 9 \\
\hline $1^{*}$ & $\begin{array}{c}12 \% \\
(3 / 25)\end{array}$ & $\begin{array}{c}36 \% \\
(4 / 11)\end{array}$ & $\begin{array}{c}22 \% \\
(8 / 36)\end{array}$ & $\begin{array}{c}37 \% \\
(13 / 35)\end{array}$ & $\begin{array}{c}12 \% \\
(5 / 42)\end{array}$ & $\begin{array}{c}44 \% \\
(12 / 27)\end{array}$ & $\begin{array}{c}28 \% \\
(5 / 18)\end{array}$ & $\begin{array}{c}73 \% \\
(11 / 15)\end{array}$ & $\begin{array}{c}53 \% \\
(8 / 15)\end{array}$ \\
\hline 2 & $\begin{array}{c}9 \% \\
(4 / 46)\end{array}$ & $\begin{array}{c}0 \% \\
(0 / 10)\end{array}$ & $\begin{array}{c}36 \% \\
(8 / 22)\end{array}$ & $\begin{array}{c}21 \% \\
(8 / 38)\end{array}$ & $\begin{array}{c}4 \% \\
(1 / 23)\end{array}$ & $\begin{array}{c}35 \% \\
(9 / 26)\end{array}$ & $\begin{array}{c}27 \% \\
(3 / 11)\end{array}$ & $\begin{array}{c}40 \% \\
(6 / 15)\end{array}$ & $\begin{array}{c}13 \% \\
(2 / 15)\end{array}$ \\
\hline 3 & $\begin{array}{c}0 \% \\
(0 / 24)\end{array}$ & - & $\begin{array}{c}17 \% \\
(3 / 18)\end{array}$ & $\begin{array}{c}0 \% \\
(0 / 14)\end{array}$ & $0 \%$ GS & $\begin{array}{l}15 \% \\
(2 / 13)\end{array}$ & $\begin{array}{l}11 \% \\
(1 / 9)\end{array}$ & $\begin{array}{c}20 \% \\
(3 / 15)\end{array}$ & $0 \%$ \\
\hline 4 & - & - & $0 \%$ GS & - & - & GS & $0 \%$ GS & $0 \%$ & - \\
\hline 5 & - & - & - & - & - & $\begin{array}{c}28 \% \\
(5 / 18)\end{array}$ & - & - & - \\
\hline 6 & - & - & - & - & - & $\begin{array}{c}35 \% \\
(8 / 23)\end{array}$ & - & - & - \\
\hline 7 & - & - & - & - & - & $\begin{array}{c}8 \% \\
(2 / 24)\end{array}$ & - & - & - \\
\hline 8 & - & - & - & - & - & $\begin{array}{c}18 \% \\
(2 / 11)\end{array}$ & - & - & - \\
\hline 9 & - & - & - & - & - & $\begin{array}{c}0 \% \\
(0 / 7)\end{array}$ & - & - & - \\
\hline
\end{tabular}

$\mathrm{GS}=$ Geen staalname, enkel klinische evaluatie

* De eerste behandelingsronde bij bedrijf 8 en 9 bestaat uit een eenmalige injectie met moxidectine 10\% LA.

drijven de minderheid, met $2 \%$ die aangeeft dat het probleem niet onder controle te krijgen lijkt (Sarre et al., 2012). Op alle opgevolgde bedrijven kon het schurftprobleem na enkele maanden onder controle gekregen worden, waarbij alle dieren klinisch gezond en/of parasitologisch negatief waren. Op korte termijn was het toepassen van een intensieve behandelingsstrategie dus succesvol. Hierbij dient opgemerkt te worden dat vooraf telkens een diagnose gesteld werd aan de hand van huidafkrabsels om het type schurft te bepalen, wat een essentieel onderdeel is van een efficiënte schurftbestrijding, cf. www.dgz.be/publicatie/ fiche-aanpak-schurft.

Het aantal behandelingen dat nodig was om tot een schurftvrije bedrijfssituatie te komen, bleek bedrijfsafhankelijk te zijn, waarbij grotere bedrijven meer behandelingen nodig hadden om volledig negatief te worden. Dit werd reeds beschreven op schapenbedrijven en kan verklaard worden doordat het grotere aantal dieren voor meer onderling contact zorgt en voor meer verplaatsingen tussen verschillende stallen, wat het spreidingsrisico vergroot (Falconi et al., 2002). Bovendien werden niet alle dieren bemonsterd per bedrijfsbezoek, waardoor dieren met kleine letsels of asymptomatische dragers over het hoofd konden gezien worden. Uit de resultaten blijkt daarenboven dat hetzelfde product een verschillende werkzaamheid kan vertonen op verschillende bedrijven. De aanwe- zigheid van bedrijfsspecifieke mijtenstammen met een verschillende pathogeniciteit en/of gevoeligheid voor MLs kan hier de oorzaak van zijn. Dit fenomeen werd in het verleden reeds beschreven bij schapen en runderen in de VS (Roberts en Meleney, 1970).

Ook al kwam dit in deze studie niet duidelijk naar voor, toch kan het toepassen van een suboptimaal bedrijfsmanagement, i. e. voeding, huisvesting, etc., eveneens een rol spelen bij het al dan niet persisteren van een schurftinfectie op bedrijfsniveau (Sarre et al., 2012), aangezien dit management de weerstand van de dieren en daardoor de respons op behandeling kan beïnvloeden. Hoewel één behandeling met een ML in het verleden efficiënt bleek te zijn tegen Psoroptesschurft (Aiello, 1998; Clymer et al., 1997; Lonneux et al., 1997; Pouplard en Detry, 1981), blijkt dat in de praktijk minimum twee behandelingen (één behandelingsronde) nodig zijn om klinische verbetering te bekomen (Minihan et al., 2002; Vercruysse en Rew, 2002). Op probleembedrijven zoals in deze studie waar vaak klinisch zwaar aangetaste dieren voorkomen, vereist de controle of eradicatie van schurft vaak zelfs meer dan één behandelingsronde van twee MLinjecties. Hier dient echter opgemerkt te worden dat de dosis van de gebruikte MLs in de voorliggende studie gebaseerd werd op het geschat gewicht van de dieren, waardoor onderdosering als oorzaak van therapiefalen niet kon uitgesloten worden. Onderdosering en 
Tabel 3. Gemiddelde "scratch index" (SI), "clinical index" (CI) en "mite counts" (MC) van alle dieren voor en na behandeling en het aantal dieren waarop nog levende mijten aanwezig waren (n) na behandeling op bedrijf 8 en 9.

\begin{tabular}{|c|c|c|c|c|c|c|c|c|}
\hline \multirow[b]{2}{*}{$\mathbf{n} \mathbf{T} \mathbf{x}^{*}$} & \multicolumn{3}{|c|}{ Bedrijf 8} & \multicolumn{5}{|c|}{ Bedrijf 9} \\
\hline & n & SI & CI & MC & n & SI & CI & MC \\
\hline 0 & 15 & 3,7 & $\begin{array}{c}10,3 \\
(3,1-6,6)\end{array}$ & $\begin{array}{c}953 \\
(6-5590)\end{array}$ & 15 & 3,2 & $\begin{array}{c}10,2 \\
(2,3-20,6)\end{array}$ & $\begin{array}{c}465 \\
(1-3156)\end{array}$ \\
\hline 1 & 11 & 3,1 & $\begin{array}{c}6,2 \\
(1,1-24,9)\end{array}$ & $\begin{array}{c}102 \\
(0-670)\end{array}$ & 8 & 1,5 & $\begin{array}{c}4,2 \\
(0,3-13,7)\end{array}$ & $\begin{array}{c}26 \\
(0-250)\end{array}$ \\
\hline 2 & 6 & 2,4 & $\begin{array}{c}4,7 \\
(0-21,4)\end{array}$ & $\begin{array}{c}3 \\
(0-26)\end{array}$ & 2 & 0,7 & $\begin{array}{c}2,1 \\
(0-4,3)\end{array}$ & $\begin{array}{c}1 \\
(0-10)\end{array}$ \\
\hline 3 & 3 & 0,7 & $\begin{array}{c}4,6 \\
(0,9-21,1)\end{array}$ & $\begin{array}{c}1 \\
(1-4)\end{array}$ & 0 & 0,7 & $\begin{array}{c}3,2 \\
(0-6)\end{array}$ & 0 \\
\hline 4 & 0 & 0,5 & $\begin{array}{c}0,9 \\
(0-3,1)\end{array}$ & 0 & 0 & 0,3 & $\begin{array}{c}1,1 \\
(0-1,7)\end{array}$ & 0 \\
\hline
\end{tabular}

* $\mathrm{n} \mathrm{Tx}=$ aantal behandelingsrondes: behandelingsronde 1: eenmalige injectie met moxidectine 10\% LA; behandelingsrondes 2-4: 2 injecties met moxidectine 1\% met 7-10 dagen interval. In behandelingsronde 1 werden alle dieren behandeld. In behandelingsrondes 2-4 werden enkel de dieren met levende mijten behandeld.

het frequent en/of incorrect gebruik van MLs kunnen eveneens het ontstaan van resistente mijtstammen in de hand werken. Tot op heden is echter nog geen in-vitrotest beschikbaar voor het detecteren van MLresistentie bij $P$. ovis-mijten.

Ondanks de zichtbare klinische en parasitologische verbetering was ook met de LA-formulatie van moxidectine verdere opvolging nodig. Er werd een gelijkaardig resultaat bekomen in een Engelse studie uit 2012 waarbij een eenmalige injectie met Cydectin 10\% LA (Zoetis, België) onvoldoende bleek om de infectie onder controle te houden (Mitchell et al., 2012), hoewel in een voorgaande studie (Losson et al., 2008) de dieren volledig schurftvrij waren na één behandeling met Cydectin 10\% LA (Zoetis, België) voor een periode van minimum 77 dagen, in aanwezigheid van onbehandelde en schurftpositieve dieren. Niettegenstaande heeft een LA-formulatie als voordeel dat de eerste behandelingsronde kan vervangen worden door een eenmalige injectie, wat de werkdruk van de veehouder kan verlichten. Bovendien bleek dat op bedrijf 8 en 9 de bijkomende opvolgbehandelingen succesvol waren op groepsniveau, ook al gebeurden deze behandelingen enkel bij de schurftpositieve dieren.

Tot slot blijft de vraag hoe de dieren die negatief waren gedurende de winter, opnieuw positief konden worden tijdens of na het weideseizoen. De meest waarschijnlijke oorzaak is het voorkomen van subklinisch aangetaste dragers op het bedrijf. Deze runderen zijn klinisch gezond, maar op specifieke plaatsen zijn toch schurftmijten aanwezig in een zogenaamde latente fase, waarbij geen symptomen geïnduceerd worden. Bij schapen worden de infra-orbitale en inter- digitale fossae, de oren en het perineum aangeduid als mogelijke plaatsen waar de mijten resideren (Bates, 2012), maar bij het rund is hierover weinig bekend. Zelfs bij staalname van de volledige kudde kunnen dragers over het hoofd gezien worden, omdat deze latente mijten zich vaak niet op de predilectieplaatsen bevinden. Een andere mogelijke oorzaak is herinfectie vanuit de omgeving. Waar voordien werd aangenomen dat de voornaamste infectieweg het direct contact tussen dieren onderling is (Bates, 2012; Hourrigan, 1979; Minihan et al., 2002; Losson, 2003), werd stalhygiëne recent geïdentificeerd als een significante risicofactor voor Psoroptes-schurft, wat suggereert dat omgevingsbesmetting mogelijk is (Sarre et al., 2012). $P$. ovis-mijten kunnen vrij lang in de omgeving overleven, maar ze verliezen hun infectiviteit na een paar weken (Bates, 2012; Pegler en Wall, 2004; Smith et al., 1999), waardoor het op de opgevolgde bedrijven onwaarschijnlijk lijkt dat de ingeweide dieren op deze manier herbesmet zouden zijn geraakt.

Er kan geconcludeerd worden dat de volledige eliminatie van schurft op een BWB-bedrijf een zeer moeilijke taak is. Op korte termijn is het toepassen van een intensief behandelingsschema in combinatie met een aangepast management, zoals het scheren vóór behandeling, zeer effectief. Door de mogelijke aanwezigheid van subklinische dragers of acaricidenresistentie en het aanhouden van een suboptimaal bedrijfsmanagement is de kans echter groot dat de ziekte vroeg of laat opnieuw opduikt in de kudde. Een snelle diagnose is daarom van belang om tijdig een correcte therapie te starten, waardoor de ziekte sneller onder controle kan gekregen worden. 


\section{DANKBETUIGING}

De auteurs willen graag de bedrijfsdierenartsen en veehouders bedanken die aan deze studie meegewerkt hebben, alsook Zoetis, voor de gedeeltelijke financiering van de studie.

\section{REFERENTIES}

Aiello S.E. (1998). Integumenatry system. In: Aiello S.E. (editor). The Merck Veterinary Manual. Eighth edition, Merck \& Co Inc., Whitehouse Station, N.J., USA, p. 665666.

Bates P. (2012). Mites (Acari). In: External Parasites of Small Ruminants. A Practical Guide to their Prevention and Control. Cab International, Oxfordshire, UK, p. 1547.

Clymer B.C., Janes T.H., McKenzie M.E. (1997). Evaluation of the therapeutic and protective efficacy of doramectin against psoroptic scabies in cattle. Veterinary Parasitology 72, 79-89.

Cole N.A., Guillot F.S. (1987). Influence of Psoroptes ovis on the energy metabolism of heifer calves. Veterinary Parasitology 23, 285-295.

Falconi F., Ochs H., Deplazes P. (2002). Serological crosssectional survey on psoroptic sheep scab in Switzerland. Veterinary Parasitology 109, 119-127.

Guillot F.S., 1981. Population increase of Psoroptes ovis (Acari: Psoroptidae) on stanchioned cattle during summer. Journal of Medical Entomology 18, 44-47.

Hourrigan J.L. (1979). Spread and detection of psoroptic scabies of cattle in the United States. Journal of the American Veterinary Medical Association 175, 1278-1280.

Lonneux J.-F., Nguyen T.Q., Detry J., Farnir F., Losson B.J. (1998). The relationship between parasite counts, lesions, antibody titres and daily weight gains in Psoroptes ovis infested cattle. Veterinary Parasitology 76, 137-148.

Lonneux J.-F., Nguyen T.Q., Losson B.J. (1997). Efficacy of pour-on and injectable formulations of moxidectin and ivermectin in cattle naturally infected with Psoroptes ovis: parasitological, clinical and serological data. Veterinary Parasitology 69, 319-330.

Losson B. (2003). Les gales et les poux chez les bovins. Point Vétérinaire 234, 24-29.

Losson B.J., Lonneux J.-F., Lekimme M. (1999). The pathology of Psoroptes ovis infestation in cattle with a special emphasis on breed difference. Veterinary Parasitology 83, 219-229.

Losson B., Hanosset R., Lekimme M., Mignon B., Deroover E. (2008). Evaluation of the persistent efficacy of Cydectin (Moxidectin) 10\% LA injectable against Psoroptes ovis in naturally infested cattle in Belgium. In:
Proceedings of the 25th World Buiatrics Congress. Budapest, Hungary, 2008.

Lusat J., Morgan E.R., Wall R. (2009). Mange in alpacas, llamas and goats in the UK: Incedence and risk. Veterinary Parasitology 1963, $179-184$.

Minihan D., Barrett D.J., Mulcahy G., Cassidy J.P. (2002). Psoroptes ovis infestation in a Belgian Blue bull. Irish Veterinary Journal 55, 168-171.

Mitchell E.S., Jones J.R., Foster A.P., Millar M., Milnes A., Williams J. (2012). Clinical features of psoroptic mange in cattle in England and Wales. Veterinary Record 170, 359.

O’Brien D.J. (1999). Treatment of psoroptic mange with reference to epidemiology and history. Veterinary Parasitology 83, 177-185.

Pegler K.R., Wall R. (2004). Tactic responses of the parasitic mite, Psoroptes ovis, to light and temperature. Experimental and Applied Acarology 33, 69-79.

Personne F., Marty G., Brun H. (2006). Behandeling van Sarcoptes scabiei bij het schaap. Het Dierenartsen Weekblad 56, 16-18.

Plant J.W. (2006). Sheep ectoparasite control and animal welfare. Small Ruminant Research 62, 109-112.

Pouplard L., Detry M. (1981). Un progrès spectaculaire dans la lutte contre la gale bovine: Utilisation d'un nouvel agent antiparasitaire systémique: l'ivermectine. $A n$ nales de Médecine Vétérinaire 125, 643-650.

Rehbein S., Visser M., Winter R., Trommer B., Matthes H.F., Maciel A.E., Marley S.E. (2003). Productivity effects of bovine mange and control with ivermectin. Veterinary Parasitology 114, 267-284.

Sarre C., De Bleecker K., Deprez P., Levecke B., Charlier J., Vercruysse J., Claerebout E. (2012). Risk factors for Psoroptes ovis mange on Belgian Blue farms in Northern Belgium. Veterinary Parasitology 190, 216-221.

Smith K.E., Wall R., Berriatua E., French N.P. (1999). The effects of temperature and humidity on the off-host survival of Psoroptes ovis and Psoroptes cuniculi. Veterinary Parasitology 83, 265-275.

Stromberg P.C., Guillot F.S. (1989). Pathogenesis of psoroptic scabies in Hereford heifer calves. American Journal of Veterinary Research 50, 594-601.

Roberts I.H., Meleney W.P. (1970). Variations among strains of Psoroptes ovis (Acarina: Psoroptidae) on sheep and cattle. Annals of the Entomological Society of America 64, 109-116.

Taylor M.A., Coop R.L., Wall R.L. (2007). Parasites of cattle. In: Veterinary Parasitology. Third edition, Blackwell Publishing, Oxford, UK, p. 143-145.

Vercruysse J., Rew R.S. (2002). The (persistent) efficacy of MLs against cattle ectoparasites. In: Macrocyclic Lactones in Antiparasitic Therapy. CABI Publishing, Oxford, UK, 199-202. 